\title{
Novas ocorrências e descrição da fêmea de Mysteria darwini (Lameere) (Coleoptera, Vesperidae, Anoplodermatinae) ${ }^{1}$
}

\author{
Manoel Martins Dias ${ }^{2}$
}

\begin{abstract}
${ }^{1}$ Realizado com auxílio do Programa BIOTA/FAPESP.
${ }^{2}$ Departamento de Ecologia e Biologia Evolutiva, Universidade Federal de São Carlos. Caixa Postal 676, 13565-905 São Carlos-SP, Brasil.
\end{abstract}

\begin{abstract}
New records and description of the female of Mysteria darwini (Lameere) (Coleoptera, Vesperidae, Anoplodermatinae). The female of Mysteria darwini (Lameere, 1902) is described for the firs time and new records for the species in south Brazil are added. The female has short antennae, small eyes, wings shorter than in male and the hind tibial spur is reduced.
\end{abstract}

Keywords. Anoplodermatinae; female description; Mysteria darwini; new records; Vesperidae.

Resumo. A fêmea de Mysteria darwini é descrita e novos registros da espécie no sul do Brasil são fornecidos. A fêmea tem antenas curtas, olhos pequenos, as asas são mais curtas do que as do macho e o esporão tibial posterior é reduzido.

Palavras-Chave. Anoplodermatinae; descrição da fêmea; Mysteria darwini; novos registros; Vesperidae.

Os Anoplodermatinae estão atualmente incluidos na família Vesperidae (SvÁcha et al. 1997). A tribo Mysteriini, revista em DiAs (1988), inclui os gêneros: Mysteria Thomson, 1860, Pathocerus Waterhouse, 1901 e Pseudopathocerus Dias, 1988. Até o momento era conhecida apenas a fêmea de Pathocerus wagneri Waterhouse, 1901. Para Mysteria darwini (Lameere, 1902), a descrição da fêmea e novas localidades de ocorrência são ora apresentadas.

O material examinado pertence às coleções citadas a seguir, acompanhadas dos nomes de seus responsáveis e das siglas correspondentes: MCNZ, Museu de Ciências Naturais, Fundação Zoobotânica do Rio Grande do Sul, Porto Alegre (M. H. M. Galileo); MZSP, Museu de Zoologia, Universidade de São Paulo, São Paulo (U. R. Martins); UFSCAR, Departamento de Ecologia e Biologia Evolutiva, Universidade Federal de São Carlos, São Carlos (M. M. Dias).

Mysteria darwini (Lameere, 1902) (Figs. 1-8)

Anoploderma (Mysteria) Darwini Lameere, 1902: 210.

Mysteria darwini; Lane, 1937: 218; Dias, 1988: 142, figs. 1,7,17,33,47,70-71,77,81; Monné, 1994: 15.

Fêmea (Fig. 1). Coloração castanho-avermelhada. Antenas curtas, não ultrapassam a margem posterior do pronoto; artículos antenais 3-10 fracamente denteados; artículos 9-11 com cobertura densa de cerdas curtas; artículo 11 alongado, com terço apical delimitado ou não por constrição irregular, mais evidente do lado externo (Fig. 7). Olhos pequenos, amplamente separados entre si nas áreas anterior e inferior da cabeça (Figs. 2, 3). Mandíbulas com dois dentes na margem interna, variáveis na forma. Último artículo dos palpos maxilares e labiais alongado (Fig. 2). Pronoto com pontuação grosseira e densa nas margens anterior e laterais; torna-se mais fina e esparsa nas áreas central e posterior; superfície com protuberâncias que podem ser bastante acentuadas; destacamse dois lobos centrais na margem anterior e área elevada central, próxima à margem posterior. Élitros luzidios, com pontuação fina e esparsa. Asas membranosas com extremidade reduzida e afilada (Fig. 5); em repouso, com extremidade dobrada, chegam até o quarto segmento do abdome; no macho, as asas em repouso chegam até a extremidade do abdome. Face ventral dos artículos 1-3 dos tarsos anteriores e medianos, com escovas laterais e faixa mediana central com cerdas esparsas; mesmos artículos nos tarsos posteriores, face ventral, com cerdas densas laterais e faixa mediana central glabra, com algumas cerdas. Artículos 1-3 dos tarsos (Fig. 6), proporcionalmente mais curtos que aqueles do macho. Esporões tibiais com fórmula 2-2-1; esporão posterior bastante reduzido, mais curto que as cerdas apicais da tíbia (Fig. 4). Genitália com coxitos moderadamente largos, arredondados no ápice (Fig. 8).

Dimensões, em mm. Comprimento total, 35,0 - 44,0; comprimento do pronoto, 5,6-8,4; maior largura do pronoto, $7,3-10,1$; comprimento do élitro, 26,0-31,0; largura umeral, $10,8-13,8$.

Material examinado (24 machos, 6 fêmeas). BRASIL. Santa Catarina: Florianópolis, fêmea, 21.II.1976, M. H. Galileo col. (MCNZ); macho, 9.XII.1990, M. Pagani col. (MCNZ); Garopaba, 3 machos, 14 - 20.II.1988, L. Moura col. (MCNZ). Rio Grande do Sul: Osório, 4 

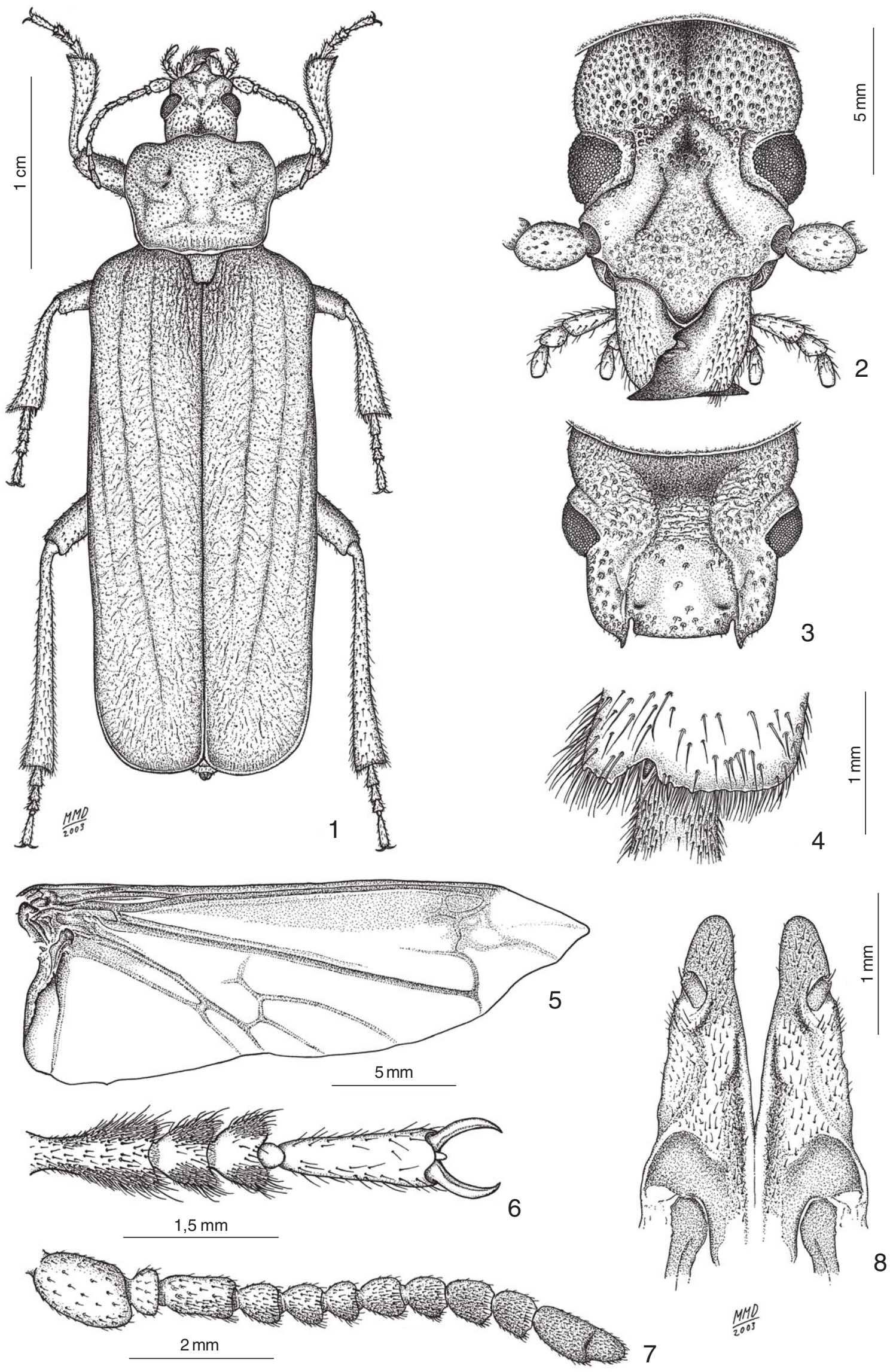

Figs. 1-8. Mysteria darwini, fêmea: 1, dorsal; 2, cabeça, frontal; 3, cabeça, ventral; 4, tíbia posterior, extremidade com esporão, ventral; 5, asa membranosa; 6, tarso anterior, ventral; $\mathbf{7}$, antena; 8 , genitália, coxitos, ventral. 
machos, 27.XII.1978, R. Hoffmann col. (MCNZ), 4 machos, J. Raymundo col. (MCNZ); Terra de Areia, macho, 5 fêmeas, M. Botton col. (UFSCAR), 10 machos (MZSP), macho (MCNZ), XII.1994, G. Longo \& S. J. Soria col.

\section{DISCUSSÃO}

Na fêmea de $M$. darwini, as asas membranosas mais curtas que aquelas do macho e parcialmente reduzidas no ápice (Fig. 5), mostram a tendência de redução dessas estruturas nas fêmeas de Anoplodermatinae, relacionada a hábitos subterrâneos. Duas outras situações, em fêmeas de Anoplodermatini, são: asas muito reduzidas, em forma de pequena lâmina com nervação vestigial, nos gêneros Migdolus Westwood, 1863, Acanthomigdolus Bruch, 1941, Paramigdolus Dias, 1986, Anoploderma Guérin-Méneville, 1840 e Sypilus Guérin-Méneville, 1840 (Dias 1984, 1986); asas membranosas ausentes em Hypocephalus Desmarest, 1832 (LAMEERE 1902; Dias 1987).

Agradecimentos. À Dra. Maria Helena M. Galileo pelo empréstimo de exemplares, ao Dr. Ubirajara R. Martins por sugestões e pelo acesso ao material da coleção sob sua responsabilidade e ao Dr. Marcos Botton pelo envio de exemplares.

\section{REFERENNCIAS}

DiAs, M. M. 1984. Revisão da subfamília Anoplodermatinae. Parte I. Tribo Anoplodermatini. Gênero Migdolus Westwood, 1863 (Coleoptera, Cerambycidae). Revista Brasileira de Entomologia 28(4): 507-535.

Dias, M. M. 1986. Revisão da subfamília Anoplodermatinae. Parte II. Tribo Anoplodermatini. Gêneros: Acanthomigdolus Bruch, 1941, Paramigdolus, gen. n., Anoploderma Guérin-Méneville, 1840, Sypilus Guérin-Méneville, 1840 (Coleoptera, Cerambycidae). Revista Brasileira de Entomologia 30(1): 115-139.

Dias, M. M. 1987. Revisão da subfamília Anoplodermatinae. Parte III. Tribo Anoplodermatini. Gêneros: Cherrocrius Berg, 1898, Hypocephalus Desmarest, 1832 (Coleoptera, Cerambycidae). Revista Brasileira de Entomologia 31(1): 101-112.

Dias, M. M. 1988. Revisão da subfamília Anoplodermatinae. Parte IV. Tribo Mysteriini. Gêneros: Mysteria Thomson, 1860, Pathocerus Waterhouse, 1901, Pseudopathocerus, gen. n. (Coleoptera, Cerambycidae). Revista Brasileira de Entomologia 32(2): 139160 .

Lameere, A. 1902. Révision des Prionides. Deuxième mémoire. Anoplodermines. Annales de la Societé Entomologique de Belgique 46: 191-225.

Lane, F. 1937. Esboço monographico dos Anoplodermídeos. Revista do Museu Paulista 23: 153-223.

Monné, M. A. 1994. Catalogue of the Cerambycidae (Coleoptera) of the Western Hemisphere. Part XII. São Paulo, Sociedade Brasileira de Entomologia, 56 p.

SVÁCHA, P.; J. WANG \& S. CHEN. 1997. Larval morphology and biology of Philus antennatus and Heterophilus punctulatus, and systematic position of the Philinae (Coleoptera: Cerambycidae and Vesperidae). Annales de la Societé Entomologique de France (N.S.) 33(3): 323-369. 